\title{
$\mathrm{VII} \mathrm{CINCCI}$
}

VII Colóquio internacional sobre Comércio e Cidade

Fortaleza, 03 a 07 de Novembro de 2020

\section{O ambiente e a arquitetura comercial: uma análise sob o ponto de vista da emoção e do visual merchandising}

The environment and commercial architecture: an analysis from the point of view of emotion and visual merchandising

El entorno y la arquitectura comercial: un análisis desde el punto de vista de la emoción y el merchandising visual

OLIVEIRA, Natan Noel Soares de; Bacharel; Faculdade Santa Maria (FSM) noel.olvr@outlook.com

FIGUEIREDO, Camilla Furtado de; Mestre; Universidade Federal da Paraíba (UFPB)

camilla.furtado@cear.ufpb.br

FIGUEIREDO, Gildivan Martins de; Bacharel; Faculdade Santa Maria (FSM)

gildivanmartins@gmail.br

\section{Resumo}

O presente artigo avalia a implementação de estratégias para motivação do cliente no ambiente do ponto de vendas, através de técnicas empregadas ao branding emocional e o visual merchandising na arquitetura da loja Attitude Urban localizada na cidade de Cajazeiras-PB. Para tanto foi utilizada o método de pesquisa exploratório, para analisar os aspectos supracitados relacionado as características da loja física, e aos aspectos sensoriais atribuído a marca e ao ambiente analisado. Buscou-se identificar a empregabilidade de técnicas de visual merchandising e branding emocional, em suas ações e campanhas de conscientização, bem como das ações de marketing digital em redes sociais e suas estratégias de convencimento do cliente. Constatou-se o direcionamento do marketing sensorial ao público alvo da loja que está atrelada a inovação e juventude. Sendo que a loja Attitude Urban se preocupa em relação aos detalhes tangíveis e intangíveis que proporcionam um melhor resultado no ambiente comercial.

Palavras-chave: Arquitetura sensorial. Branding emocional. Visual merchandising.

The environment and commercial architecture: an analysis from the point of view of emotion and visual merchandising

\section{Abstract}

This article evaluates the implementation of strategies for the customer's motivation in the point of sale, through techniques used in the emotional branding and visual 


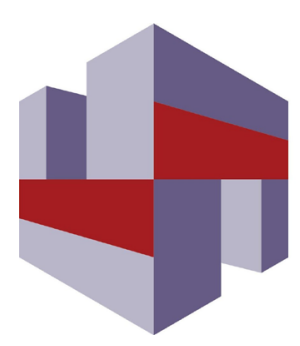

\section{CINCCI}

VII Colóquio internacional sobre Comércio e Cidade

Fortaleza, 03 a 07 de Novembro de 2020

merchandising in the Attitude Urban store architecture, located in Cajazeiras-PB. For this purpose, the exploratory research method was used to analyze the aspects related to the physical store characteristics, and the sensory aspects attributed to the brand and the environment analyzed. Sought if to identify the employability of visual merchandising and emotional branding techniques, in their actions and awareness campaigns, as well as the digital marketing actions in social networks and their strategies of convincing the client. It was found, the sensory marketing targeting the store's target audience, that is linked to innovation and youth. Being that the store Attitude Urban is concerned with the tangible and intangible details that provide a better result of the commercial environment.

Keywords: Sensory architecture. Branding emotional. Visual merchandising.

\section{El entorno y la arquitectura comercial: un análisis desde el punto de vista de la emoción y el merchandising visual}

\section{Resumen}

Este artículo evalúa la implementación de estrategias para la motivación del cliente en el entorno del punto de venta, a través de técnicas utilizadas para el branding emocional y el merchandising visual en la arquitectura de la tienda Attitude Urban ubicada en la ciudad de Cajazeiras-PB. Para este propósito, el método de investigación exploratoria se utilizó para analizar los aspectos antes mencionados relacionados con las características de la tienda física y los aspectos sensoriales atribuidos a la marca y al entorno analizado. Intentamos identificar la empleabilidad de la comercialización visual y las técnicas de marca emocional en sus campañas y campañas de sensibilización, así como las acciones de marketing digital en las redes sociales y sus estrategias para convencer al cliente. Se descubrió que la dirección del marketing sensorial para el público objetivo de la tienda estaba vinculada a la innovación y la juventud. La tienda Attitude Urban se preocupa por los detalles tangibles e intangibles que proporcionan un mejor resultado en el entorno comercial.

Palabras clave: Arquitectura sensorial. Branding emocional. Visual Merchandising. 


\section{Introdução}

O acesso à informação está cada vez mais facilitado nos últimos anos pela internet. $\mathrm{O}$ e-commerce ganha espaço e gera novos consumidores bem informados e habituados tanto, a exigência nas suas necessidades pela qualidade do produto e preços convidativos, quanto ansiosos pela facilidade e comodidade no consumo, afetando o desempenho das lojas físicas. Enquanto isso, as tendências se renovam de forma exponencial e, portanto, buscar novas formas de estratégias e ações é essencial para as organizações comerciais de estrutura físicas se destacarem do mercado on-line. A compreensão da imagem da organização formulada pelos clientes é importante para determinar seu desempenho e, assim, o nível de satisfação deles.

O consumidor contemporâneo não deseja apenas comprar ou consumir um determinado produto ou serviço. O estudo de De Toni et al. (2008, p.1, apud ENGEL, et al., 2000), determina que, "Sendo a satisfação (ou a insatisfação) do cliente um dos estágios terminais e a consequência última do processo de decisão do cliente", enquanto Tumelero e Baldissera (2015, p.13), complementam que, "a qualidade do produto, a experiência vivida na loja e os significados associados à marca farão com que este cliente retorne a loja.". Assim, além de buscar um produto e serviço de qualidade, o consumidor contemporâneo busca também experiências emocionais e sensoriais que lhe promovam liberdade e bem-estar.

Com isso, grandes e pequenas empresas estão buscando novas estratégias, atribuindo o branding ${ }^{1}$ emocional e o visual merchandising ${ }^{2}$ para alavancar suas vendas, e nesse conceito, elementos emocionais se destacam na arquitetura em forma dos sentidos - visão, audição, olfato, paladar e tato. Também se destacam, determinantes como cidadania, liberdade, status, harmonia e confiança, que permite o consumidor sentir-se familiarizado com o espaço, criando um vínculo afetivo.

É, de fato, importante identificar e destacar as empresas que atribuem o visual merchandising e o branding emocional em seus espaços, assim como, buscar entender de qual forma estão atribuindo esse conceito em seus ambientes, criando laços com os seus consumidores, seja através do espaço social físico, quanto digital.

Para isso, o presente artigo tem como intuito apresentar um estudo da importância do ambiente comercial, destacando os aspectos físicos e sensoriais aplicado ao branding emocional e ao visual merchandising que contribuem no comportamento positivo do consumidor final na marca, e na loja varejista Attitude Urban localizada na cidade de Cajazeiras no estado da Paraíba.

\footnotetext{
1 Branding: é o gerenciamento da marca em suas diversas expressões, o que inclui entre outros trabalhos, a programação visual, as campanhas publicitárias e o trabalho feito no ponto de contato pelo design de interiores (TUMELERO; BALDISSERA, 2015, p.1).

${ }^{2}$ Visual merchandising: procura através da percepção visual e sensorial uma maneira de seduzir o cliente a entrar em determinado ambiente e que ele se sinta bem em permanecer naquele espaço, a fim de vender seu produto promovendo uma experiência que ligue o consumidor ao mesmo (CAVALCANTE; ALBINO, 2019, p.4).
} 


\section{Referencial Teórico}

\subsection{Os cinco sentidos}

A constituição dos cincos sentidos se relaciona diretamente com o ambiente e com a maneira em que o corpo recepciona um espaço e se identifica com ele. A tabela 1 identifica as expressões sensoriais relacionando a cada sensor humano.

Tabela 1 - Relação dos sensores humanos às sensações e expressões sensoriais.

\begin{tabular}{|c|c|c|}
\hline Sensores & Sensações & Expressões sensoriais \\
\hline $\begin{array}{l}\text { Sensor do } \\
\text { cheiro }\end{array}$ & Atmosférica & $\begin{array}{l}\text { Congruência do produto, intensidade atmosférica, advertência e } \\
\text { marca olfativa e assinatura acentuada. }\end{array}$ \\
\hline $\begin{array}{l}\text { Sensor do } \\
\text { som }\end{array}$ & Auditiva & $\begin{array}{l}\text { Jingle, voz e música ambiente, atenção e assinaturas sonoras } \\
\text { temáticas e marca auditiva }\end{array}$ \\
\hline $\begin{array}{l}\text { Sensor } \\
\text { visão }\end{array}$ & Visual & $\begin{array}{l}\text { Desing, embalagem e estilo da cor, luz e tema gráfico, exterior e } \\
\text { interior }\end{array}$ \\
\hline $\begin{array}{l}\text { Sensor } \\
\text { gusto }\end{array}$ & $\begin{array}{l}\text { Gastronômic } \\
\text { o }\end{array}$ & $\begin{array}{l}\text { Interação, simbiose e sinergias de nome, apresentação e } \\
\text { conhecimento do ambiente, estilo de vida e prazer }\end{array}$ \\
\hline $\begin{array}{l}\text { Sensor } \\
\text { tato }\end{array}$ & Tátil & Materiais e temperatura de superfície, peso e estabilidade \\
\hline
\end{tabular}

Fonte: Traduzido a partir de Rupini Nandagopal (2014, p. 3).

Como revisado na tabela 1 , cada sentido é responsável por estimular sensações distintas no ser humano. Individualmente cada uma delas é capaz de identificar características no espaço e atribuí-las a um significado pessoal.

O primeiro contato com o objeto é feito através da visão e posteriormente os outros sentidos se apresentam em suas expressões sensoriais. Em consequência a mente armazena essas informações através de lembranças positivas relacionadas ao prazer, alegria e excitação, possivelmente os transformando em objetos de contemplação.

\subsection{Arquitetura Sensorial}

O espaço natural exprime do ser humano sensações que são atribuídas aos sentidos do corpo, criando memórias capazes de tornar os lugares familiares. Segundo Rheingantz et al. (2004, p.2), é "um mundo onde os sentidos atuam como condutores de uma realidade exterior que reverbera na alma do indivíduo".

A arquitetura sensorial busca atribuir as características do espaço natural explorando o uso dos sentidos humanos, criando ambientes inclusivos e experiências emocionais que desenvolvem a consciência do lugar como uma relação entre objeto e pessoa: "Existe contato entre a mente e seus objetos; um sentimento específico de prazer, desprazer ou neutralidade; um discernimento do objeto; uma intenção em relação ao objeto; uma atenção para com o objeto." (VARELA, et al., 2003, p. 81).

Ainda em relação a Varela et al. (2003), além das questões materiais e estéticas do espaço e ambientes (mundo), na arquitetura sensorial é imprescindível 
atribuir sensações, experiências sensoriais e percepções (mente), "Isso vem de encontro ao conceito de arquitetura sensorial, uma arquitetura que considera todos os sentidos e não apenas o visual. O que interessa é a sensação da pessoa no ambiente, isso integra a percepção auditiva, visual, tátil, olfativa e gustativa." (TUMELERO; BALDISSERA, 2015, p.1). Rheingants et al. (2004, p.2), complementa que:

A união entre mundo e mente implica em aceitar que os objetos tangíveis (materiais) produzidos pelos arquitetos não conferem, por si sós, qualidade e eficiência, uma vez que sua aceitação e eficiência estão diretamente relacionadas com os aspectos intangíveis. (RHEINGANTZ, et al., 2004, p.2).

Segundo Varela et al. (2003), A capacidade cognitiva é atribuída ao que experimentamos, e está relacionado ao que vemos, ouvimos, cheiramos, tocamos e provamos, o que liga diretamente as nossas experiencias emocionais construídas a própria relação com o espaço. A pele deve sentir o vento e os materiais, os olhos enxergar as cores e as luzes, a língua os sabores, o nariz alcançar os cheiros, enquanto os ouvidos devem alcançar os sons, "as lembranças que um determinado cheiro desperta; os sentimentos provocados pelo sol que entra pela janela e toca a pele; o som dos cheios e vazios que tomam um lugar familiar." (RHEINGANTZ, et al. 2004, p.4).

Portanto, na arquitetura sensorial há a necessidade de consagrar a união entre mundo e mente na produção de ambientes inclusivos, e isso é fomentado relacionando os sentidos do ser humano e os aspectos espaciais e materiais construtivos "que sejam capazes de considerar a matéria como condutora dos sonhos do ser humano que se emociona com as sensações por ela despertadas." (RHEINGANTZ, et al. 2004, p.4).

\subsection{Branding emocional}

Branding ou, gestão da marca, sempre esteve presente no meio urbano e na vida cotidiana das pessoas. A marca é e sempre foi associada a campanhas publicitárias, e símbolos que buscam interagir com as decisões de consumo das pessoas. "É verdade que todo o mundo sabe o que é uma marca, porque vivemos rodeados de marcas e assediados por elas, mas a resposta à pergunta "o que é uma marca' varia conforme a quem perguntemos." (COSTA, 2011, p.17).

Como aborda Costa (2011), o questionamento sobre "o que é uma marca" pode variar trazendo sentidos distintos para cada pessoa. Para alguns a marca é apenas, de forma superficial, uma maneira de marcar, "uma marca é o sinal que deixa o ato de marcar, a marcação de uma matriz ou um traço sobre uma superfície." (COSTA, 2011, p. 20). Para outros, a marca possui um sentido mais intangível ligada ao valor emocional, exigindo uma gestão mais aprimorada, como classificado por Gobé (2006, apud TUMELERO; BALDISSERA, 2015, p.2), "fala que a gestão de marca ou branding também tem se voltado para o valor das experiências emocionais ou sensoriais, principalmente aquelas que criam um significado para as pessoas". Assim Silva (2016, p.3434), conclui:

Portanto, pode-se concluir que a marca abrange esses diversos conceitos, pois ela reúne os elementos tangíveis como o nome, logotipo e embalagem, importantes para identificar o produto ou serviço. E é também 
os aspectos intangíveis, sua reputação perante os indivíduos. (SILVA, 2016, p.3434).

O branding emocional segundo Ramos (2012. p.87), que classifica-o como branding sensorial, defende que, para se adequar as novas exigências do consumidor o modo de atrair o consumidor mudou, "hoje, pensa-se muito mais em como envolver o produto às emoções do comprador, do que apenas vendê-lo. E é nesse contexto que o branding sensorial é colocado em destaque". Gobé (2002) afirma que, "nos seus estudos apresenta o conceito de branding emocional, cuja base está no caráter humano, nas experiências, no desejo de ir além da satisfação material." (apud Silva, 2016. p.3435). Ramos (2012, p.88), alega que:

\begin{abstract}
Desse modo, o branding sensorial é uma nova estratégia com a qual as empresas objetivam ligar a marca ao consumidor por meio de ações que estimulam os cinco sentidos, pois a influência sensorial impacta diretamente no estado emocional do indivíduo que, consequentemente, cria vínculo e acrescenta valor à marca. Assim, o branding sensorial é uma ramificação da forma de se desenvolver o branding em uma organização. Há várias nomeações para esse tipo de estratégia; alguns a definem como marketing experimental, marketing emocional, marketing sensorial ou sensorialidade e, ainda, brand experience. (RAMOS, 2012. p.88).
\end{abstract}

Portanto, o branding emocional em suas inúmeras definições possui um sentido direto, tangível e principalmente intangível, ligado a valores emocionais e da marca, "[...] que propõe a gerência da marca no âmbito das aspirações, dos ideais e da experiência, em que o consumo torna-se uma consequência do relacionamento marca e indivíduo." (SILVA, 2016. p. 3435). Fica claro a importância do vínculo entre marca, espaço e usuário para determinar a ligação existente com o cliente, de forma a garantir o envolvimento do mesmo em suas distintas características.

\title{
2.4 Visual merchandising na arquitetura
}

O visual merchandising surge como desdobramento do merchandising na década de 1980 com a crescente difusão dos produtos eletrônicos e a recessão global (MORGAN, 2011). A necessidade de reinventar a forma de atrair clientes e, assim como, a forma de fazê-los permanecerem dentro do espaço, interagindo com os produtos nas prateleiras e vitrine, era essencial para as organizações não perderem força mercadológica.

Hoje com a crescente exponencial das organizações proveniente das tecnologias e da internet, a disputa de mercado está mais acirrada. Com isso, segundo Morgan (2011, p.15), "Hoje o visual merchandising é uma ferramenta indispensável para o desenvolvimento comercial e a construção de identidade de uma empresa que deseja ter reconhecimento e sucesso no seu ramo de atuação".

A arquitetura tem uma ligação direta no visual merchandising, sendo ambos essenciais para a conexão das pessoas e o espaço, segundo Cavalcante e Albino (2019, p.6), "a arquitetura é de fundamental importância nesse elo que existe entre cliente e produto, pois é ela quem fornece a ambientação adequada para que aconteça esse encontro". Para Blessa (2003, p.22), Visual Merchandising é a:

Técnica de trabalhar o ambiente do ponto de venda criando identidade e personificando decorativamente todos os equipamentos que circundam os produtos. O Merchandising Visual usa o design, a arquitetura e a 
decoração para aclimatar, motivar e induzir os consumidores à compra. (BLESSA, 2003, p.22).

A estética do ambiente e sua capacidade de excitação é essencial para a familiarização do espaço no subconsciente do cliente. Cavalcante e Albino (2019, p.11), afirma que "[...] o consumidor pode se resumir no prazer da beleza (estética) ou interesse (excitação), com isso a marca precisa saber o que é preciso estimular para escolher a ambientação e disposição dos produtos no interior da loja". Esse fato induz as pessoas para dentro do espaço e consequente permanecem por mais tempo. Detalhes como a exibição do produto, o layout, os materiais, as cores, sons, iluminação e texturas permeiam no olhar do observador de forma que os detalhes tornam a ser associadas individualmente a marca.

\section{Metodologia}

Foi utilizado o método de pesquisa exploratória com a finalidade de analisar os aspectos emocionais e sensoriais na marca Attitude Urban e sua respectiva loja varejista de moda masculina e feminina. A figura 1 apresenta um diagrama conceitual da estrutura metodológica do artigo trabalhado ao decorrer do texto.

Como mostra a figura 1 , a estrutura metodológica segue um conceito linear iniciado pela revisão bibliográfica onde foi abordado os principais termos para a fundamentação do artigo. A revisão bibliográfica resulta em uma síntese que auxilia o entendimento da análise e dos resultados da pesquisa. A partir desse ponto, a estrutura metodológica apresenta os resultados e a discussão obtidas na pesquisa.

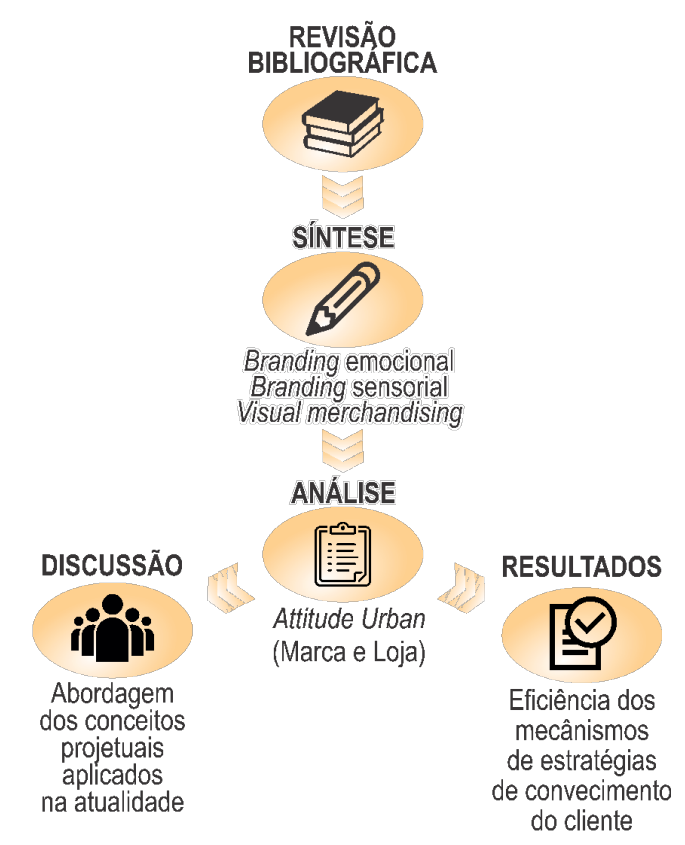

Figura 1: Diagrama conceitual da estrutura metodológica do artigo.

Fonte: Elaborado pelo autor, 2019.

Como objeto de estudo, foi selecionado a loja varejista Attitude Urban, localizado no centro da cidade de Cajazeiras, estado da Paraíba. Loja que está 
sendo cada vez mais demandada por um público que parte de adolescente à adultos, cativados pela comercialização de produtos de moda masculina e feminina como roupas, calcados e acessórios. E pela acessibilidade a produtos ligados a cultura pop hodierna.

Visando aplicar os conceitos teóricos apresentados anteriormente, a finalidade é alcançar uma metodologia capaz de identificar os parâmetros de branding emocional ligados a marca, e sensoriais ligados ao ambiente comercial. Dessa forma está descrito abaixo o método, que é baseado nas teorias do autor Marc Gobé, e as definições baseadas no referencial teórico.

O modelo de análise dos parâmetros emocionais ligado á marca parte de princípios definido pelo autor Marc Gobé (2006), que analisa cinco principais "determinantes emocionais": cidadania, liberdade, status, harmonia e confiança (ver tabela 02). Serão coletadas as respectivas informações, imagens e publicidade encontrado nas redes sociais da marca. Enquanto aos aspectos sensoriais, esses serão avaliados através de observação in loco. Buscando caracterizar aspectos ligados ao branding sensorial e ao visual merchandising na estrutura física da loja.

Tabela 2 - Arquétipo das identidades emocionais.

\begin{tabular}{|c|c|c|c|c|c|}
\hline $\begin{array}{l}\text { Determinante } \\
\text { s emocionais }\end{array}$ & Cidadania & Liberdade & Status & Harmonia & Confiança \\
\hline $\begin{array}{l}\text { Aspiração do } \\
\text { consumidor }\end{array}$ & $\begin{array}{l}\text { "Amor ao } \\
\text { mundo" }\end{array}$ & $\begin{array}{l}\text { "Amor a } \\
\text { emoção" }\end{array}$ & "Amor à classe" & $\begin{array}{c}\text { "Amor à } \\
\text { tribo" }\end{array}$ & "Amor à ética" \\
\hline $\begin{array}{l}\text { Promessa } \\
\text { emocional }\end{array}$ & $\begin{array}{c}\text { ENGAJAMEN- } \\
\text { TO }\end{array}$ & FUGA & GLAMOUR & $\begin{array}{l}\text { CONVIVÊN- } \\
\text { CIA }\end{array}$ & SEGURANÇA \\
\hline $\begin{array}{l}\text { Motivação do } \\
\text { consumidor }\end{array}$ & $\begin{array}{c}\text { Fazer o bem e } \\
\text { sustentabilidad } \\
\text { e } \\
\text { Justiça } \\
\text { Igualdade } \\
\text { humanidade }\end{array}$ & $\begin{array}{c}\text { Libertar-se } \\
\text { Estímulo } \\
\text { Sobrevivênci } \\
\text { a } \\
\text { Risco } \\
\text { Mudança }\end{array}$ & $\begin{array}{c}\text { Brilhar } \\
\text { Reconheciment } \\
\text { o } \\
\text { Previsibilidade } \\
\text { Arte } \\
\text { Prazer }\end{array}$ & $\begin{array}{c}\text { Compartilha } \\
\text { r } \\
\text { Alegria } \\
\text { Conexão } \\
\text { Celebração } \\
\text { Renovação } \\
\text { Família }\end{array}$ & $\begin{array}{c}\text { Administração } \\
\text { Conheciment } \\
\text { o } \\
\text { Soluções } \\
\text { Herança } \\
\text { Apoio }\end{array}$ \\
\hline
\end{tabular}

Fonte: Gobé (2006, apud TUMELERO; BALDISSERA, 2015 p.2).

Será necessário o cruzamento das informações coletadas do objeto de estudo com a revisão bibliográfica, e para isso o estudo dos resultados obtidos serão tratados com caráter essencialmente qualitativo.

\section{Resultados}

\subsection{Branding emocional na marca Attitude Urban}

A Attitude Urban é uma marca recente que vem se difundiu no último ano através da loja física e das redes sociais. Com ideais contemporâneos e dentro dos determinantes emocionais atribuídos por Gobé (2006), aplica na sua marca três delas: cidadania, harmonia e status.

O determinante emocional cidadania tem como promessa emocional engajamento, e a marca Attitude Urban em sua missão, estabelece o foco no cliente demostrando o interesse em atender as suas necessidades. A aparência despojada do ambiente interno colabora para a criação de um laço emocional com o público 
alvo, ao mesmo tempo em que cuidados como a aplicação dos materiais, qualidade sonora e conforto visual são bem tratados no espaço (ver figura 2). Isso permite que a marca atenda a todas as classes sociais relacionadas entre o público masculino e feminino, "as marcas cidadãs trazem o irresistível apelo ao engajamento." (TUMELERO, et al. 2015, p.7).

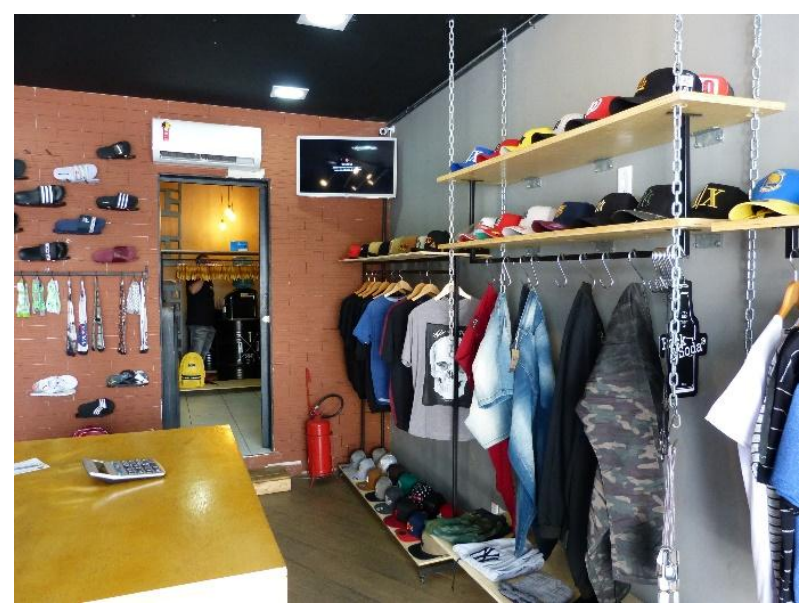

Figura 2: Fotografia do ambiente interno da loja Atittude Urban.

Fonte: Acervo próprio, 2019.

Em um pouco mais de um ano da reinauguração a marca Attitude Urban vem demostrando engajamento nas campanhas nacionais de conscientização em combate ao suicídio e câncer de mama. Nas suas redes sociais a marca busca identificar as cores relacionadas as campanhas em sua logo principal e nas publicidades digitais (ver figura 3 ).

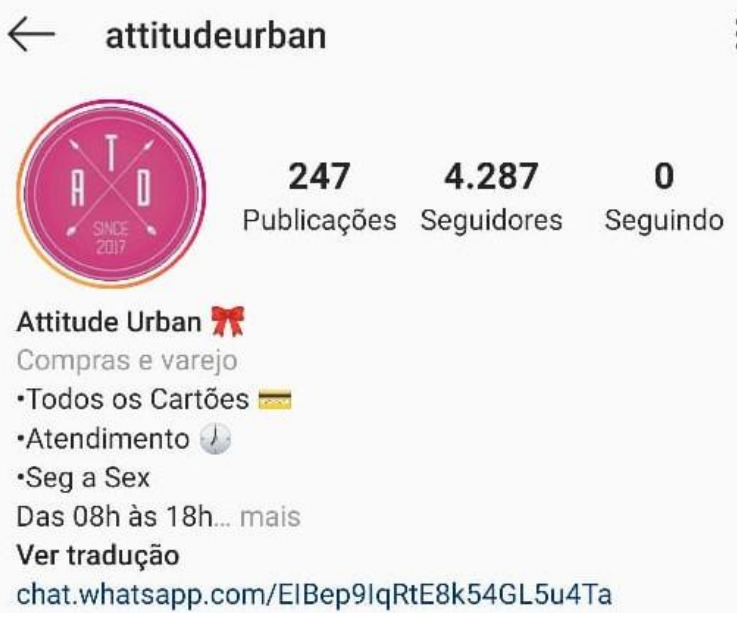

Figura 3: Página na rede social.

Fonte: Página da Attitude Urban no Instagram (2019).

A valorização da vida e os cuidados da mulher cria laços entre pessoas e comunidades, é uma forma de ligar afetivamente clientes à marca e promover a conscientização. Para Tumelero et al. (2015, p.8), essa ligação "é uma conexão muito poderosa que une filhos, amigos, homens mulheres num único grupo e permanece viva ao longo do tempo inter gerações". Essa abordagem permite a 
marca criar laços afetivos, o que está diretamente ligado a emoção, e faz com que a marca permaneça no mercado, "as marcas que conseguem se vincular ao consumidor, com esse tipo de abordagem, pretendem permanecer no mercado de forma duradoura." (TUMELERO, et al., 2015, p.8).

Fazer o bem também está associado a responsabilidade socioambiental, e nesse quesito a marca Attitude Urban promove entretenimento ligado a cultura e esporte, e demostra preocupação com meio ambiente através de atitudes simples. É armazenado a água proveniente das unidades de ar-condicionado para serem reaproveitada para higienização do ambiente diminuindo o uso da água potável para esses fins.

A maior parte da publicidade é aplicado através de panfletos digitais compartilhados em redes sociais reduzindo significativamente materiais impressos (Ver figura 4). Quando os materiais são impressos o formato do panfleto é reduzido, ou seja, é abaixo do padrão encontrado atualmente no mercado, reduzindo assim a necessidade de matéria prima. O conteúdo publicado nos panfletos é minimalista e apresenta código QR que permite direcionar o público diretamente para as plataformas digitais. Isso permite apresentar no panfleto apenas informações diretas e suscintas, enquanto no conteúdo digital é apresentado as maiores e mais detalhadas informações.

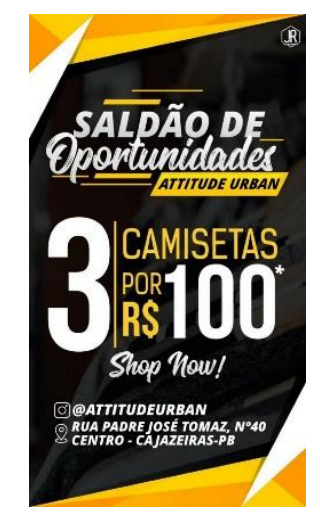

Figura 4: Panfleto digital da loja Attitude Urban.

Fonte: Página da Attitude Urban no Instagram (2019).

A marca foi responsável por promover em 2019 o primeiro torneio de Skate e a primeira batalha de rap, com o intuído de gerar socialização e promoção das atividades ligada ao público alvo. Em ambos os eventos a marca premiou e promoveu os vencedores, gerando humanidade e satisfação (ver figura 5). 


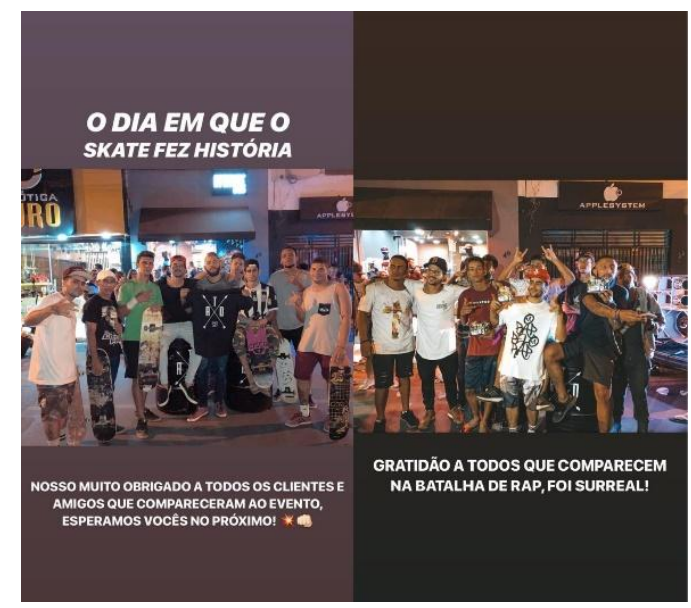

Figura 5: Registro em rede social.

Fonte: Página da Attitude Urban no Instagram (2019).

A Attitude Urban possui ações que promove o determinante emocional harmonia que traz consigo a promessa emocional de convivência. É comum em publicações nas redes sociais imagens de pessoas em grupos enfatizando o apelo do desejo de estar e pertencer a uma tribo. Isso traz para o consumidor a ligação ao estilo de celebração a vida, aos amigos, a relação de estar em reunião com pessoas pertencentes ao mesmo estilo de vida, compartilhando alegria, conexão e celebração (ver figura 6).

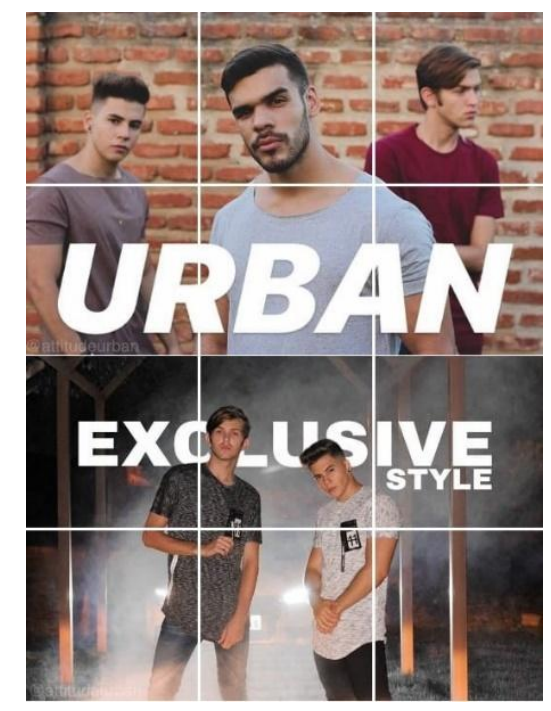

Figura 6: Publicidade da Attitude Urban.

Fonte: Página da Attitude Urban no Instagram (2019).

A marca traz consigo uma alusão ao estilo jovem moderno, pois, promove sempre atualização nas tendências dos produtos e no espaço. A loja está sempre em constante mudança no layout e mobiliário, buscando atender as necessidades do consumidor contemporâneo que está permanentemente em busca de novidades.

Em algumas campanhas publicitárias os próprios clientes se tornam modelos para as peças do vestuário. Esse posicionamento gera ao consumidor que participa 
da ação, visibilidade e reconhecimento, promove sua imagem pública e valorização como influenciador digital nas redes sociais.

O uso da campanha "\#useATD" nas redes sociais cria uma conexão com o consumidor e a marca. É uma prática da empresa promover algumas vendas feitas durante o expediente nas redes sociais através de fotografia, utilizando campanhas como citado acima, promovendo a foto do cliente com o produto consumido, gerando um laço afetivo entre as partes. Com isso se tornou comum clientes exigirem a fotografia e a publicação nas redes sociais, isso comprova que a as campanhas nas redes sociais colabora diretamente com as vendas.

Essa atitude está ligada ao determinante emocional status que tem como promessa emocional o glamour. As pessoas buscam se conectar a marca através de suas próprias redes sociais associando-se em suas publicações as campanhas da empresa (ver figura 7). Elas mesmas tiram fotos com os produtos comprados, ou utilizando as peças de vestuário adquiridos para publicar nas suas próprias redes sociais enfatizando a marca, e com isso, fica evidente a valorização da marca através da conexão com o consumidor. A busca por reconhecimento e visibilidade demostra o ganho em prestígio e qualidade, e principalmente, a autopromoção da marca sem esforços comerciais.
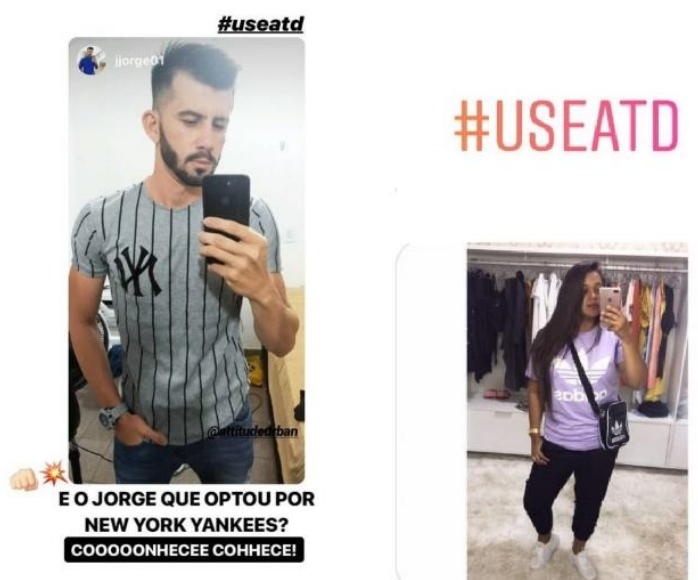

Figura 7: Publicação em rede social.

Fonte: Página da Attitude Urban no Instagram.

Cavalcante e Albino (2019, p.18), afirma que "se o cliente visualiza o produto como algo comum ele pode comprar apenas uma vez, mas se ele observar que existe exclusividade naquilo que está consumindo ele irá criar um sentimento pela marca e uma necessidade de usá-la". Portanto, o resultado da valorização da marca, dos produtos e o poder de recompra, é fruto do prestígio ligado aos usuários que compartilham o sucesso de vendas da marca.

A constituição dos cincos sentidos se relaciona diretamente com o ambiente e com a maneira em que o corpo recepciona um espaço e se identifica com ele. A tabela 1 identifica as expressões sensoriais relacionando a cada sensor humano.

\subsection{Branding sensorial e visual merchandising na loja Attitude Urbana}

Alguns aspectos sensoriais e emocionais são identificados na estrutura e espaço da loja Attitude Urban, assim como algumas estratégias de visual 
merchandising. Planejar espaços convidativos e confortáveis colabora para a aceitação e permanência do cliente, "o cliente não consegue definir exatamente porque o ambiente tem uma atmosfera diferente, e por que tudo é mais evidente, mas ele sente que o ambiente desperta a atenção." (TUMELERO, 2015, p.10).

A loja possui iluminação sutil e quente focada no fundo da loja criando camadas de sobreposições entre vitrine e espaço interno, isso induz ao cliente entrar na loja. Outro fator de iluminação induzida está nos projetores instaladas no teto que gera iluminação direcionada focando os expositores instalados nas paredes laterais, e consequentemente ajuda a destacar as texturas encontradas nas paredes criando uma harmonização de luz e sombras nos pequenos detalhes do revestimento (ver figura 8).

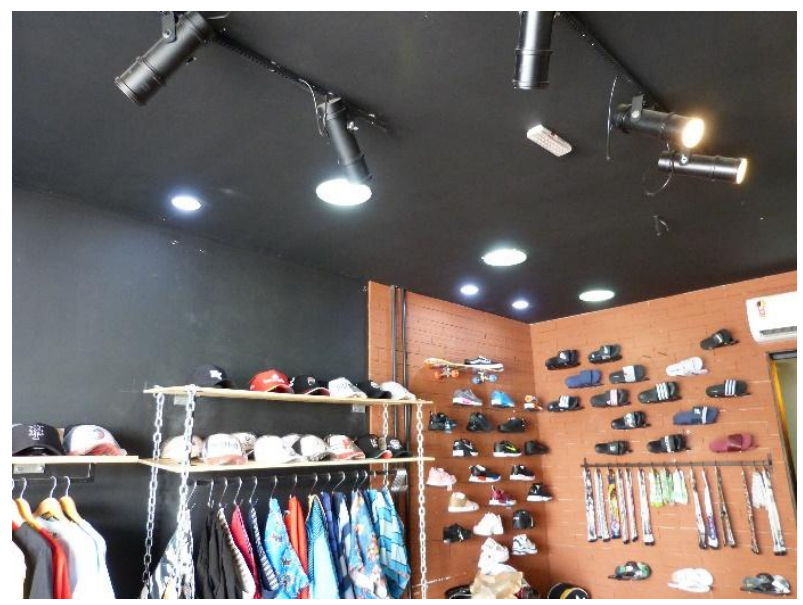

Figura 8: Ambiente interno da loja Attitude Urban.

Fonte: Acervo próprio, 2019.

Esse tipo de iluminação permite ao cliente ter um percurso contínuo com foco direto nos produtos expostos, "As formas reforçam a ideia e induzem no pensamento a vontade de entrar, de andar por esse caminho e conhecer a loja." (TUMELERO, 2015, p.11).

Um segundo fator que contribui para o percurso direcionado do cliente é o posicionamento das peças de mobiliário, ou seja, do layout. Na Attitude Urban, a maior parte dos expositores estão instalados nas paredes (ver figura 9).

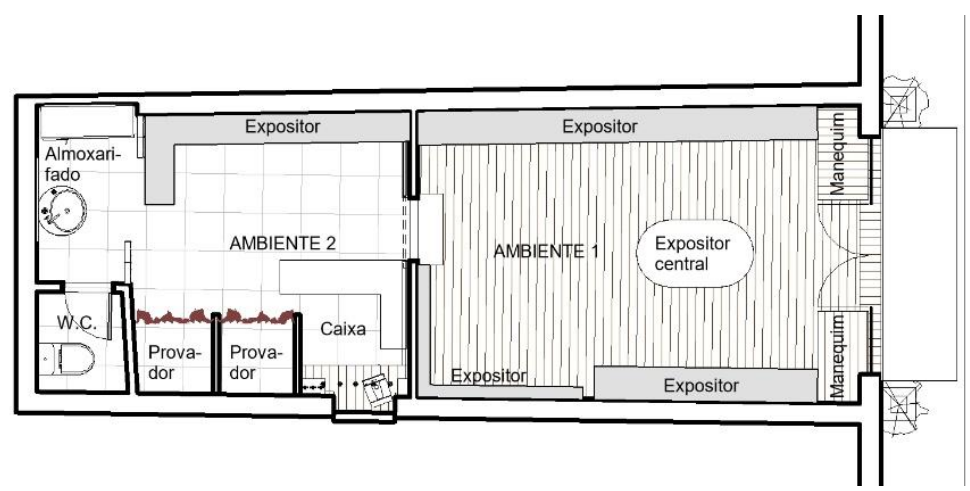

Figura 9: Desenho esquemático do ambiente interno em planta baixa (sem escala definida).

Fonte: Elaborado pelo autor, 2019. 
Devido a limitação do espaço interno apenas um expositor central está disponível, e esse expositor é modulado e móvel possibilitando, durante o dia, a exposição de diversos acessórios em diferentes posições. A circulação de um espaço comercial é definida por Granado e Moraes (2017, p.10), como:

[...] algo fundamental a ser considerado, sendo que o usuário deve ser estimulado e orientado a seguir um determinado trajeto dentro do estabelecimento. Um recurso para orientar o usuário a percorrer este trajeto são os pontos focais e as linhas de visão. Os pontos focais podem ser expositores, produtos cuidadosamente dispostos, ou qualquer coisa que atraia a atenção do consumidor e o estimule. As linhas de visão são linhas imaginárias que orientam o consumidor para determinadas áreas, $\mathrm{e}$ estas devem ser utilizadas em conjunto com os pontos focais, afim de que após seguir uma linha de visão o olhar do consumidor repouse sobre um ponto focal (GRANADO; MORAES, 2017, p.10).

Os expositores laterais, da forma dispostas, são convidativos e bem iluminado e confortável. São divididos em dois grupos onde apresenta parte instalado na parede, sem possibilidade de movimentação, e parte no piso, onde esses são móveis e frequentemente mudam de posição demarcando circulações no intuito de inovar no posicionamento do layout para cada tipo de produto ou campanha de venda durante o ano.

Outro aspecto sensitivo e emotivo está ligado as texturas e ao sentido tátil, elas podem configurar sensações de temperaturas como cálido e frígido. 0 aconchego é uma sensação importante para a permanência do cliente dentro da loja, em relação a isso Chiarelli (2013 apud TUMARELO, 2015, p.12), afirma que "[...] ainda, ao nível sensorial, o uso de um material frio, como o concreto aparente, juntamente com a madeira, que torna o ambiente mais cálido.”. O tijolo aparente também é um material que promove sensação de aconchego por sua cor, rusticidade e textura porosa.

O ambiente da Attitude Urban integra materiais característicos nos elementos construtivos, tão como no mobiliário. No primeiro espaço, é notado no piso um porcelanato que remete a textura de madeira em lâminas (ver figura 10), nas paredes a maior parte é composta por acabamento em pintura acrílico cinza e uma pequena parte de tijolos sintéticos aparente. No segundo espaço o piso é composto por cerâmica enquanto as paredes acompanham o revestimento encontrado no primeiro espaço, apenas com adição de elementos vazados em concreto aparente. Já o mobiliário, todo ele é composto por madeira e metal. 


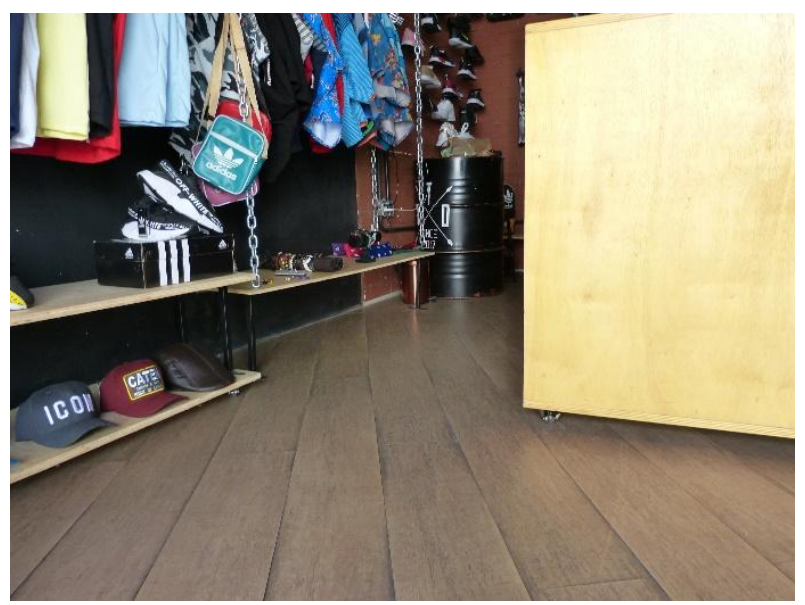

Figura 10: Ambiente interno da loja Attitude Urban destacando acabamento do piso e paredes.

Fonte: Acervo próprio, 2019.

O paladar é ativado por estratégias gastronômicas, a loja busca oferecer aperitivos que influencia na permanência do cliente e no prolongamento do uso do espaço. É possível em alguns momentos, a loja oferecer comida como massas salgadas e adocicadas, acompanhado de expressos ou cervejas, atendendo a diversificação das preferências dos consumidores.

O espaço da loja não contempla sensações olfativas, porém aborda sensações auditivas determinadas pelo som ambiente instaladas em caixas acústicas. Os aspectos convidativos e de permanência se dá pela seleção da trilha sonora composta na sua maior parte por música MPB e músicas alternativas como rock e rap, cativando o gosto musical do público alvo o convidando para permanecer por mais tempo dentro da loja. A tabela 3 exibe um resumo dos determinantes emocionais e sensoriais identificados no objeto de estudo.

Tabela 3 - Resumo dos determinantes emocionais e sensoriais identificado no objeto de estudo.

\begin{tabular}{|cc|cc|}
\hline \multicolumn{2}{|c|}{ MARCA } & \multicolumn{2}{c|}{ LOJA } \\
\hline $\begin{array}{c}\text { Determinante } \\
\text { s emocional }\end{array}$ & Satisfaz? & Sensor & Satisfaz? \\
\hline CIDADANIA & Sim & CHEIRO & Não \\
\hline LIBERDADE & Não & SOM & Sim \\
\hline STATUS & Sim & VISÃO & Sim \\
\hline HARMONIA & Sim & GOSTO & Sim \\
\hline CONFIANÇA & Não & TATO & Sim \\
\hline
\end{tabular}

Fonte: Elaborado pelo autor (2019).

Como visto na tabela 3 , a marca e a loja física atribuem mais de um determinante emocional e sensorial, sendo marca ou uma loja capaz de possuir mais de um determinante emocional e sensorial, quanto mais determinantes possuir 
mais se adequará ao público alvo. As ligações da marca e do ambiente proporcionam experiencias diversificadas ao consumidor engajando-o ao comprometimento e a fidelidade à loja.

\section{Considerações finais}

Percebe-se na marca Attitude Urban a atenção no processo de oferta de produto ao cliente, existe uma preocupação em relação a detalhes intangíveis que a cada dia está sendo mais aplicado nos ambientes comerciais. No decorrer do estudo foram observados diversos fatores ligados ao comportamento e influência de compra do consumidor, são esses, fatores tangíveis relacionado ao visual merchandising e intangíveis relacionado ao branding emocional e sensorial abordado em sua estratégia de convencimento do cliente.

A sustentação no mercado e o desenvolvimento da marca comprova a eficiência de estratégias como o branding emocional e o visual merchandising no planejamento de marketing visual e ambiente sensorial da loja. A ligação afetiva dos consumidores com a marca reflete diretamente no comportamento de compra e recompra dos clientes e no favorecimento de potenciais compradores cativado pelo auto divulgação atribuída através dos clientes nas redes sociais.

É importante refletir acerca de como estão sendo abordados os processos de projeto arquitetônico atualmente. Entender que o consumidor a cada dia está mais exigente - quanto ao espaço que faz uso - é necessário e essencial para um resultado de um bom planejamento arquitetônico no ambiente comercial. O design deve entender o contexto de um ponto de venda, relacionar a decoração e a logística do ambiente de forma a atender as exigências do cliente. Buscar aclimatar e dar significados e sentidos ao espaço gera ao consumidor uma ligação familiar e a sensação de acolhimento e bem-estar, prolongando o tempo do uso do espaço e atribuindo sentido a necessidade de recompra do cliente.

Portanto, no espaço da loja Attitude Urban verificamos a ligação entre os aspectos físicos e a identidade da marca, a sintonia entre elas revela o posicionamento positivo diante o mercado que a cada dia se torna mais exigente e informada. Entendemos o significado das promessas motivacionais que leva o consumidor a se deslocar de sua casa em busca de um produto, e de um ambiente que atenda às suas necessidades físicas e emocionais. $E$ entendemos, por fim, a importância dada a atribuição dos sentidos na marca e no espaços.

\section{Referências}

ATTITUDE URBAN [Imagens]. Instagram: @attitudeurban, 2019. Disponível em: https://www.instagram.com/attitudeurban/ Acesso em: 05 nov. 2019.

BLESSA, Regina. Merchandising no ponto-de-venda. 2. Ed. São Paulo: Atlas, 2003. 
CAVALCANTE, Emmanuel dos Santos; ALBINO, Danilo Alves. A importância do visual merchandising para a arquitetura comercial. 2019. 19 f. TCC (PósGraduação) - Curso de Arquitetura e Urbanismo, Centro Universitário de João Pessoa - UNIPÊ, João Pessoa, 2019.

COSTA, Joan. A imagem da marca: Um fenômeno social. São Paulo: Rosari, 2011.

GOBÉ, Marc. Experiências emocionais. Revista D2B Design to Branding Magazine, [Toda palavra conteúdo editorial], São Paulo, p. 13-19, nov. 2006. Disponível em: https://pt.slideshare.net/arnaldorabelo/gad-design-2branding?from action=save. Acesso em: 28 de outubro de 2019.

GRANADO, Bruno Martins Campos. MORAES, Juliana Bordinhon Nogueira de. ESTRATÉGIAS COMERCIAIS: VISUAL MERCHANDISING ALIADO A ARQUITETURA. Revista Científica Semana Acadêmica. Fortaleza, ano MMXVII, No. 000105, 24/03/2017. Disponível em: https://semanaacademica.org.br/artigo/estrategias-comerciais-visualmerchandising-aliado-arquitetura. Acessado em: 29 de outubro de 2019.

MORGAN, Tony. Visual Merchandising Vitrines e Interiores Comerciais. São Paulo: Gustavo Gili, 2011.

SILVA, Elisangela Batista da; "O PAPEL DO DESIGN NA CONSTRUÇÃO DO PLACE BRANDING", p. 3432-3441 . In: Anais do $1^{\circ}$ Congresso Brasileiro de Pesquisa e Desenvolvimento em Design [= Blucher Design Proceedings, v. 9, n. 2]. São Paulo: Blucher, 2016. Disponível em: http://pdf.blucher.com.br.s3-saeast-1.amazonaws.com/designproceedings/ped2016/0295.pdf. Acesso: 22 de outubro de 2019.

RAMOS, Morgana Gonçalves. Branding sensorial: a relação marca $x$ consumidor criada pela ambientação das lojas - DOI. Universitas: Arquitetura e Comunicação Social, [s.I.], v. 8, n. 2, p.81-109, 14 mar. 2012. Centro de Ensino Unificado de Brasilia. http://dx.doi.org/10.5102/uc.v8i2.1333. Disponível em: https://www.publicacoesacademicas.uniceub.br/arqcom/article/view/1333/1539.

Acesso em: 22 out. 2019.

RHEINGANTZ, Paulo Afonso; ARAÚJO Mônica.; ALCANTARA, Denise. Os sentidos humanos e a construção do lugar: Em busca do caminho do meio para o desenho universal. In: Seminário Acessibilidade no cotidiano. Rio de Janeiro, 2004. Disponível em: http://www.prolugar.fau.ufri.br/wpcontent/uploads/2017/10/os sentidos humanos safe.pdf. Acesso em: 22 de outubro de 2019. 
RUPINI, RV.; NANDAGOPAL. A Study on the Influence of Senses and the Effectiveness of Sensory Branding. Journal of Psychiatry, v. 18, n. 2, p. 1-7, 2014. Disponivel em: file:///C:/Users/noelo/Desktop/a-study-on-the-influence-of-sensesand-the-effectiveness-of-sensory-branding-Psychiatry-1000236.pdf. Acesso em: 05 de novembro de 2019.

TONI, D.; LARENTIS, F.; MATTIA, A. ?.; MILAN, G. S. A imagem do comércio varejista e a satisfação dos consumidores: um estudo exploratório ambientado em uma cidade da Serra Gaúcha. BASE - Revista de Administração e Contabilidade da UNISINOS, v. 8, n. 1, p. 91-104, 2011. Disponível em: http://www.spell.org.br/documentos/ver/2493. Acesso em: 01 de outubro de 2019.

TUMELERO, Mônica; BALDISSERA, Adriana Diniz. A EMOÇÃO NA ARQUITETURA COMERCIAL. Revista Tecnológica / ISSN 2358-9221, [S.I.], v. 3, n. 2, p. 1-14, sep. 2015. ISSN 2358-9221. Disponível em: https://uceff.edu.br/revista/index.php/revista/article/view/76. Acesso em: 01 oct. 2019.

VARELA, Francisco; THOMPSON, Evan; ROSCH, Eleanor. A mente Incorporadora - Ciências Cognitivas e Experiência Humana. Porto Alegre: Artmed, 2003. [editado originalmente em 1991].

As referências bibliográficas deverão seguir o padrão da ABNT, o texto deve estar em Arial, corpo 12, espaçamentos de 12pt após, sem recuo. 